\title{
0 PAPEL DO ESPECTADOR NO PROCESSO DE DRAMA EDUCAÇÃO E SUA RELAÇÃO COM O FENÔMENO DA TEATRALIDADE
}

\author{
Heloíse Baurich Vidor ${ }^{1}$
}

O presente artigo pretende discutir possíveis pontos de intersecção entre a metodologia de drama educação e o conceito de teatralidade, tendo no papel do espectador o seu recorte de análise. Em que medida drama educação e teatralidade podem dialogar? Para desenvolver este propósito faremos uma discussão sobre o processo de drama educação, com base nos preceitos de Dorothy Heathcote ${ }^{2}$, no que diz respeito ao papel do espectador no drama e sua relação com conceito de teatralidade.

O termo teatralidade surgiu em paralelo ao termo literalidade e diz respeito ao que é propriamente teatral, apresentando-se como um adjetivo daquilo a que se refere. E para que o objeto receba esta qualidade é necessário que alguém o atribua, a partir de uma mirada, de uma observação imediata. Deste modo, a presença de um espectador, que atribua uma qualidade de teatralidade a uma obra, a uma pessoa, ou a uma situação, é condição sine quanon deste fenômeno denominado teatralidade.

Isso não quer dizer que ele esteja restrito ao campo teatral. A partir da Modernidade, houve uma ampla difusão deste termo em diversos campos como o campo da arte, da psicologia, da sociologia entre outros. No nosso caso, priorizaremos a abordagem deste termo no campo dos estudos teatrais, sem desconsiderá-lo como uma ferramenta de compreensão da realidade educacional, por exemplo.

${ }^{1}$ Heloise Baurich Vidor é atriz do Grupo de Teatro (E)xperiência Subterrânea de Florianópolis, diretora teatral e professora

do Departamento de Artes Cênicas da UDESC/Florianópolis. Mestre em Educação e Cultura pela UDESC e Mestranda em

Teatro no PPGT na mesma Universidade.

${ }^{2}$ Dorothy Heathcote é considerada a criadora do process drama, forma teatral inglesa, desenvolvida no contexto escolar, e equivalente ao teatro - educação brasileiro. 


\section{Urdimento}

${ }^{3}$ Conceito desenvolvido por Gavin Bolton que serve para designar a dupla realidade de ser participante e observador de suas próprias ações em um só tempo

\section{${ }^{4}$ Conceito desen-} volvido por Augusto Boal, que fala sobre a dupla realidade de ser participante e espectador no mesmo processo, mas não concomitantemente.

No processo do drama em sala de aula o espectador não existe. $\mathrm{O}$ grupo de alunos desenvolve a proposta assumindo os papéis de espectadores e atores, concomitantemente (conceito de percipiente ${ }^{3}$ ) ou alternadamente (conceito de metaxis ${ }^{4}$ ), mas de qualquer maneira, não há a presença de alguém de fora do processo, que compareça para observar.

O objetivo do processo é justamente que o aluno envolva-se com o estímulo ficcional, mas reflita sobre o mesmo, aportando elementos e circunstâncias de seu contexto, sua cultura, seus princípios e atitudes, sem necessáriamente levar esta experiência a público.

O estilo de Heathcote para a abordagem do drama opõe-se, segundo ela, à representação de personagens de um determinado texto dramático. Através de uma narrativa coletiva, que surge a partir de materiais históricos - fotos, objetos, fragmentos de texto - os alunos são colocados no contexto ficcional como participantes do mesmo, e alternando, assim, os papéis de acordo com a tessitura narrativa. Neste sentido não há um roteiro prévio que será apresentado ao aluno.

Dentro desta perspectiva pontual do processo do drama em sala de aula, será possível se falar em teatralidade como uma qualidade a ser conquistada e desenvolvida?

\section{O que entendemos como 'o eminentemente teatral'?}

Na contemporaneidade, o termo teatralidade ganhou uma ampliação de abordagem, na medida em que deixou de se relacionar prioritariamente ao campo do teatro e passou a ser utilizado para designar aspectos de outras realidades, que não somente a cênica.

Devido à própria configuração que nossa sociedade adquiriu, a partir do século XX, com a espetacularização de várias manifestações do cotidiano, o termo passou a servir para uma denominação mais adequada a esta nova maneira de o mundo se apresentar. Neste sentido, a espetacularização da sociedade afetou diretamente o próprio teatro, tanto o espaço físico como no que se refere à criação. E o papel do espectador também foi transformado, ganhando matizes diferenciados em termos de sua participação ativa no espetáculo, mas mantendo seu papel imprescindível dentro do acontecimento teatral.

Sobre isso, Degranges diz:

0 papel do espectador no processo de drama educação... Heloíse Baurich Vidor. Dezembro 2007 - № 9 
As profundas alterações no modo de vida trazidas pela contemporaneidade põem em xeque as proposições artísticas modernas e requisitam aos artistas novos procedimentos estéticos, em consonância com a percepção e sensibilidade do espectador dos nossos dias, solicitando a elaboração de propostas artísticas que se posicionem perante o horizonte de expectativas do receptor contemporâneo, que apresenta feições particulares.(DESGRANGES, 2006:1411).

Assim, o teatral não está mais relacionado estritamente ao local teatro, lugar de onde se vê o ator - aquele que concretiza a manifestação da teatralidade - através de um texto dramático que será encenado. Qualquer pessoa pode assumir aspectos de teatralidade, em qualquer lugar e circunstância, desde que alguém se lhe atribua.

Apesar de o termo nascer do universo teatral, segundo Cornago,

(...) no ha sido en el ámbito de los estudios teatrales donde primero se ha desarrollado este enfoque, sino que hay que esperar a los primeros años noventa para que empiece a aplicar de manera más sistemática a la historia y el análisis del arte escénico...(CORNAGO, 2005:3).

Conargo completa que o primeiro aspecto condicional, quando se pensa em teatralidade relacionada ou não ao campo do teatro, é o olhar do outro. Este fenômeno, portanto, só é desencadeado se houver a presença de um observador. O segundo aspecto é o caráter processual, somente ocorre quando está em funcionamento. E o terceiro é que a teatralidade é o fenômeno da representação: o fingimento que vai se desenvolver quando o ator interpreta o personagem e este fenômeno é visível para o observador, havendo um caráter intencional por parte de quem representa.(CORNAGO, 2005:4-5) Assim, um fator que potencializa a teatralidade é a ênfase na exterioridade material, a ostentação dos signos que serão utilizados na representação. $\mathrm{O}$ objetivo disto é atrair o olhar do observador, que depois de ser seduzido pela forma, encontra um vazio por trás e isso estabelece o jogo da teatralidade: o que está por trás daquilo que se representa.

\section{O lugar do espectador na aula do drama.}

No método de drama em sala de aula ${ }^{6}$, o papel do espectador como alguém de fora do processo que é convidado a apreciar uma obra "finalizada", um espetáculo, não existe. Assim, o papel de espectador no drama é desempenhado pelo próprio participante, que assume a dupla realidade de observador e atuante.

0 papel do espectador no processo de drama educação... Heloíse Baurich Vidor.
${ }^{5}$ Tradução livre :

"não foi no âmbito dos estudos teatrais onde primero se desenvolveu este enfoque, teve-se que esperar os primeiros anos da década de noventa para que se começasse a aplicar de maneira mais sistemática à história e à análise das artes cênicas, (....)" in CORNAGO, Oscar. ?Qué

es la teatralidad?

Paradigmas estéticos de la Modernidad. Telón de Fondo 1, (www.telondefondo. org), 2005:3.

${ }^{6}$ Vale apontar que a metodologia do drama pode ser utilizada no âmbito extra-curricular, inclusive para a montagem de um espetáculo teatral. Aqui estamos enfocando sua abordagem curricular.

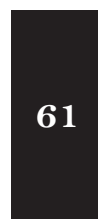




\section{Urdimento}

${ }^{7} \mathrm{~A}$ expressão "professor-personagem" foi a tradução escolhida por Beatriz Cabral para a convenção inglesa "teacher in role", devido à impossibilidade de tradução literal quanto às características que 0 uso desta estratégia adquiriu no contexto brasileiro. Segundo Cabral, a influência de Viola Spolin no Brasil, cujos procedimentos com os jogos teatrais incorporam a presença do espectador, leva 0 jogador em geral, a uma aproximação que se atém mais à caracterização do que à função social. (CABRAL, 2006: 19-20)

Esta dupla função é baseada tanto na proposta de Augusto Boal, quanto na prática de Bertold Brecht com a peça didática. Para Boal o importante não é que os espectadores apenas recebam idéias, mas que possam torná-las cênicas subindo ao palco e praticando, modificando, interferindo concreta e ativamente, no ato da exposição. Boal chama este espectador ativo de espectator e à dupla consciência deste pensar e agir de 'metaxis'.

No trabalho de Brecht com a peça didática, esta dupla realidade de atuar e refletir também estava presente. O intuito de Brecht era exercitar a discussão de temas levantados pela dramaturgia através da representação destes personagens e a troca de personagens entre o grupo era a maneira de explorar a dialética da proposição. A própria característica dramatúrgica das peças didáticas contribuíam com a possibilidade de contextualização, na medida em que funcionavam como roteiros possíveis de serem complementados com enxertos de textos, improvisações, músicas etc.

A influência tanto destas idéias de Brecht quanto de Boal na metodologia do drama fizeram com que outros termos e tratamentos variantes destes surgissem. Cecily O’Neill, por exemplo, fala do 'espectador consciente' que, para ela, implica um grupo com 'unicidade de resposta':

O contágio social opera para criar pressão em direção a uma conformidade do grupo, acordo e aceitação...o professor de drama pode controlar esta energia do grupo, ampliar seu efeito e forçar o acordo, especialmente nas fases iniciais do trabalho, para estabelecer o contexto dramático. (O’NEILL, 1989 apud CABRAL,2007: 55).

Se o professor atuar como teacher in role (professor-personagem) ${ }^{7}$, ele estabelece com o grupo uma relação de ator-espectador, não opondo os dois papéis de modo a tornar os espectadores passivos, mas criando uma relação de antagonismo que fortaleça o grupo, encorajando os alunos a assumirem papéis na trama.

Outra denominação deste processo, onde o participante opera nos dois níveis ao mesmo tempo, como ator-espectador, é o que Gavin Bolton chama de 'espectador percipiente'. Nesta proposição, a dupla realidade aconteceria concomitantemente, de maneira que a reflexão ocorresse dentro do processo dramático em ação. Cabral cita O’Neill, para esclarecer que o estado mental de ser espectador deve estar presente no fazer teatral, "pois se saímos completamente da ação para iniciarmos a reflexão, podemos descobrir que não há nada lá para se refletir”.(O’NEILL, 1989 apud CABRAL, 2007:55-56).

0 papel do espectador no processo de drama educação... Heloíse Baurich Vidor. Dezembro 2007 - № 9 
Assim, dentro da prática do drama em sala de aula, temos a possibilidade de organizarmos a ação de modo que os participantes alternemse estre as funções de atores e espectadores, atuando como platéia uns dos outros e temos a possibilidade de trabalhar com a dupla consciência de atuar e observar concomitantemente, dentro da idéia de self spectador ${ }^{8}$, espectador de si mesmo9. E a similaridade entre elas é ausência de platéia exterior ao próprio grupo.

Walter Benjamim, referindo-se ao trabalho proposto por Brecht com a peça didática, denominado jogo de aprendizagem, diz : "o jogo de aprendizagem figura como uma situação específica devido à sua pobreza de aparato, simplificando o relacionamento entre ator e espectador. Cada espectador é ao mesmo tempo um observador e um ator" (BENJAMIM,1981 apud CABRAL, 2007: 57) Assim, a origem pedagógica desta perspectiva metodológica está nas idéias de Brecht com a peça didática, onde não sendo platéias das apresentações de outras pessoas, os participantes tornam-se percepientes, espectadores de si mesmos, de seus próprios argumentos e atitudes.

\section{O diálogo possível entre o drama educação e teatralidade.}

Quando pensamos que a teatralidade relaciona-se com a busca do olhar do outro, com a busca da atenção do observador, podemos supor que haja uma impossibilidade de conexão entre drama educação e teatralidade, já que não há a presença de um espectador externo no processo em questão. No entanto, constatamos que o participante do drama, ao mesmo tempo que assume uma função de atuante, é levado a portar-se como espectador, observando e refletindo sobre a construção dramática que está em jogo.

Comovimos estafunçãode espectador podeocorrer concomitantemente e, neste sentido, o fenômeno da teatralidade, de acordo com o que argumentamos, não seria possível de ocorrer, seria o sonho de que fala Evreinov, já que aqueles que estariam sendo teatrais em sua representação ficcional estariam imersos no processo. Deste modo, faltaria o ponto de vista distanciado, que teria como função atribuir ou não a adjetivação de 'teatral' ao acontecimento observado. (EVREINOV, 1956: 65)

Quando pensamos na segunda possibilidade de trabalho, onde os participantes revesam entre observadores e atuantes, alternadamente, já se torna viável a possibilidade de teatralidade. Ainda que seja um 'espectador integrado’ ao processo, a posição distanciada faz com que seja possível a percepção da representação.
${ }^{8}$ Dorothy Heathcote criou a expressão

'self-spectator' (auto espectador) para identificar a situação aqui descrita como 'espectador de si mesmo'.

${ }^{9}$ Evreinov chama esta possibilidade de 'sonho': "El sueño es um drama de nuestra invención. Un teatro monodramático, donde uno se ve a sí mismo en una realidad imaginaria, como una inmensa película".(EVREINOV, 1956:65) Tradução livre "0 sonho é um drama de nossa invenção. Um teatro monodramático, onde 0 indivíduo se vê, a si próprio em uma realidade imaginária, como um imenso

filme." In EVREINOV, Nicolas. El Teatro en la vida. Buenos Aires. Ediciones Leviatan, 1956:65 
Dentro desta dinâmica de trabalho, o professor determina o grupo que está com o foco da cena e o grupo dos observadores, e este foco varia com bastante elasticidade, sem uma delimitação definitiva de quando se atua e quando se observa, mas, ainda assim, o adjetivo 'teatral' poderá ser atribuído. Neste caso, podemos encontrar um paralelo com a identificação do fenômeno da teatralidade no cotidiano, onde reconhecemos os códigos de expressão de determinada situação e, o que está excessivo na expressão destes códigos, apreendemos como exagerado, falso, teatral.

A questão do envolvimento do aluno no processo de drama educação perpassa por este encontro com algo que lhe chama a atenção e lhe estimula como apreciador, ao mesmo tempo que o encoraja a atuar. A situação de representação exige, como diz Eugenio Barba (BARBA, 1994: 23), uma extracotidianidade do corpo - podemos entender corpo como corpo-voz-energia; como corpo visual, como corpo lingüístico. Quando o aluno compreende que o jogo ficional estabelecido por uma situação de representação pode ser explorado com a potencialização destes signos - gestuais, vocais, visuais, lingüísticos - e que a apreciação de sua ação cênica, por seus colegas, é positiva na medida em que adquire este corpo extracotidiano, ele experimenta o prazer e encoraja-se para seguir atuando, além de ter liberdade para matizar o grau de teatralidade.

Ao contrário, quando é observador consegue disfrutar do mesmo jogo porque conhece aquele que atua, percebe o seu 'disfarce' e se surpreende com a novidade de vê-lo em outra situação diferenciada do cotidiano. Assim, uma experiência alimenta a outra e desperta nos participantes a curiosidade para inverter os papéis, comportando-se na dupla realidade consciente 'atorespectador', que é o objetivo desta proposta.

Nesta característica do papel do espectador no drama, que se dá alternadamente, a possibilidade de identificação do teatral é mais palpável, na medida em que, apesar de estar envolvido no processo, o espectador está somente observando o acontecimento, sem intervenção concreta, podendo com isso assumir um distanciamento necessário para a dinâmica de ver o que está na superfície e intuir (campo do sensível) sobre o que está velado, para depois refletir (campo da razão) sobre o que viu.

Com isso, podemos ressaltar que, ainda que seja um processo em sala de aula, como Dorothy Heathcote propõe, a valorização do eminentemente teatral se opera em melhores condições se o participante pode ocupar o papel de platéia em toda a sua dimensão, com a suficiente margem de distanciamento para poder deixar-se afetar pelas tensões provocadas pelo jogo de 'disfarçar-se (aquele que atua), reconhecer o disfarce e surpreender-se com o que se conhece e o que não se conhece, que está por trás do disfarce (aquele que observa), algo, a princípio, indescritível. 
Assim como nos espetáculos fora do âmbito de sala de aula, quando somos espectadores, e sentimo-nos impactados com a experiência do acontecimento teatral que assistimos, necessitamos de tempo para o elaborarmos racionalmente. Neste sentido, a reflexão, tão preconizada em termos pedagógicos, terá seu papel deslocado a uma segunda etapa, de modo a não esmorecer o impacto estético que o acontecimento pode causar no participante 'atuante-espectador'.

\section{Considerações finais}

A diluição da fronteira que separa ator e espectador é uma tendência do teatro contemporâneo e, neste sentido, a proposta do drama não é algo que caminhe fora do seu tempo. Aliás, há vários aspectos que podemos observar como pertencentes ao universo da poética teatral contemporânea: a fragmentação e desconstrução do texto dramático, as cenas desenvolvidas em episódios, a imersão no universo ficcional a partir das sensações provocadas pela ambientação cênica, pela música ou por rituais de canto e dança.

Este caráter performático pode ser potencializado pela ação do professor e a problematização do tema ser abordada por um viés menos racional e mais poético-sensitivo. Este me parece o ponto de conexão entre o processo de drama educação e a teatralidade, porque o fenômeno da teatralidade está relacionado mais ao campo dos sentidos e menos que ao das idéias. Este campo é que provocará no aluno o impacto necessário para que ele se mantenha interessado na proposta.

Sobre isso, Desgranges alerta: "O tédio é o maior inimigo do processo e, para que isso não ocorra, torna-se necessário que o coordenador se preocupe com variações de ritmo; com lances que toquem, emocionem, surpreendam os participantes; com ingredientes de tensão e suspense; e o estabelecimento de contraste entre uma cena e a outra, que mantenha vivo o interesse do grupo."(DESGRANGES, 2006: 130)

Desta feita, o professor de drama em sala de aula está a todo momento tendo que atrair o olhar do observador - atuante, não só como simples condutor, mas como criador de experiências provocativas, que estimulem a reflexão crítica e, mais que nada, que deixem um interrogante, algo que faça com que o aluno sinta-se imerso no processo, ao mesmo tempo que o avalie e o re-alimente.

A dupla função de ator-espectador que o participante do processo de drama educação pode desempenhar, terá na forma alternada sua possibilidade de encontro com o fenômeno da teatralidade. Desta maneira, o distanciamento do observador é necessário ao acontecimento para que este possa atribuir ao acontecimento representado a qualidade de teatral.

Dezembro 2007 - № 90 papel do espectador no processo de drama educação... Heloíse Baurich Vidor. 
Conforme colocamos, o caráter reflexivo que tornará esta experiência pedagógica, fazendo com que o aluno reflita sobre sua realidade e possa ser um agente transformador, será contemplado na medida em que o 'estado de espectador' estabelecido pela proposta do drama compreende reflexão e ação, assim a potencialização dos estímulos que verticalizem a experiência sensitiva, não invalidarão o caráter pedagógico da proposta.

A importância da reflexão sobre o papel do espectador na abordagem do drama educação desenvolvida por Dorothy Heathcote, e sua respectiva contextualização por outros professores e artistas, em outras realidades culturais levando-se em conta o fenômeno da teatralidade, possibilitará a difusão desta metodologia potencialmente tão fértil e ainda pouco experimentada, mas que, indubitavelmente apresenta sintonia com parâmetros estéticos preconizados pela contemporaneidade.

\section{Referências}

BARBA, Eugenio. A Canoa de Papel - Tratado de Antropologia Teatral. São Paulo. Hucitec, 1994.

BARBA,Eugenio e SAVARESE, Nicolai. A Arte Secreta do Ator: Dicionário de Antropologia Teatral. São Paulo. Hucitec: 2000

BOAL, Augusto. Teatro do Oprimido. Rio de Janeiro, Civilização Brasileira, 2005.

BRECHT, Bertold. Teatro Dialético, Rio de Janeiro, Civilização Brasileira, 1967.

CABRAL, Beatriz. A .V. Drama como Método de Ensino. São Paulo, Ed. Hucitec, 2006.

Dorothy Heathcote - mediação e intervenção na construção da narrativa teatral em grupo. In Licenciatura em Teatro - Textos e Temas. Org. Adilson Florentino e Narciso Teles. Uberlândia. Ed. UFU, 2007 (em impressão)

Avaliação em artes e produção do conhecimento. Anais do VIII ENDIPE - Encontro Nacional de Didática e Prática de Ensino. Florianópolis, 1996.

Cavernas - Leituras e imagens do meio ambiente através do drama. Anais do XIV SEURS Seminário de Extensão da Região Sul. Porto Alegre, 1996.

Teatro como eixo curricular nas séries iniciais. Anais do $1^{\circ} \mathrm{CONEd}-$ Congresso Nacional de Educação. Belo Horizonte, 1996.

Rituais E̊ Ética - Estruturando a Participação de Forma Teatral. ad usum delphini.

COELHO, Teixeira. Em cena, o sentido. São Paulo, Duas Cidades, 1980. 
CORNAGO, Oscar. ?Qué es la teatralidad? Paradigmas estéticos de la Modernidad. Telón de Fondo 1, (www.telondefondo.org), 2005.

DESGRANGES, Flavio. Pedagogia do teatro: provocação e dialogismo, São Paulo, Ed. Hucitec, 2006.

EVREINOV, Nicolas. El Teatro en la vida. Buenos Aires. Ediciones Leviatan, 1956.

HEATHCOTE, Dorothy. \& BOLTON, Gavin. Drama for Learning: Dorothy Heathcote's Mantle of ExpertApproach to education. Portsmouth, NH: Heinemann, 1995.

HELBO, André. Teoria Del espectáculo - El paradigma espectacular. Buenos Aires, Editorial Galerna, 1989.

KOUDELA, Ingrid. Brecht um jogo de aprendizagem. São Paulo. Edusp. 1991. Texto e Jogo. São Paulo. Ed. Perspectiva. 1999.

Brecht na Pós-Modernidade. São Paulo. Ed. Perpectiva.2001.

PAVIS, Patrice. Dicionário de Teatro. São Paulo. Perspectiva: 1999.

UBERSFELD, Anne. Para Ler o Teatro. São Paulo. Ed. Perspectiva: 2005. 